\title{
USING REAL-TIME POLYMERASE CHAIN REACTION TO STUDY THE EFFECT OF SALICYLIC ACID AND SODIUM CHLORIDE ON THE PYOCYANIN PRODUCTION OF Pseudomonas aeruginosa
}

\author{
Alaa A. Sherif, Hesham S. Nada, Amgad A. Moawad*, Ibrahim E. El- desouky, \\ Salwa M. Helmy
}

Department of Bacteriology, Mycology and Immunology, Faculty of Veterinary Medicine, Kafrelsheikh University, 33516, Egypt

${ }^{*}$ Corresponding author, E-mail: moawadamgad@gmail.com

\begin{abstract}
Pseudomonas aeruginosa is a bacterium that seizes the opportunity to cause serious infections in both man and animals. Pyocyanin is a strong virulence factor produced by $P$. aeruginosa. The present study was performed to explain the effect of salicylic acid (aspirin) and sodium chloride $(\mathrm{NaCl})$ on $P$. aeruginosa and Pyocyanin using concentrations of $1.5 \%, 3 \%$ and $6 \%$ for aspirin and $3 \%, 6 \%$ and $9 \%$ for $\mathrm{NaCl}$. The effectiveness of aspirin and $\mathrm{NaCl}$ was detected by real time PCR (qPCR). The $P$. aeruginosa isolate was from broilers suffering from septicemia in Zagazig city, Egypt. The study revealed that $6 \%$ and $9 \%$ concentration of $\mathrm{NaCl}$ had a bactericidal effect on the bacterium but $3 \%$ concentration of $\mathrm{NaCl}$ has an inhibitory effect on both the growth and the expression of Pyocyanin (by 0.5 -fold lesser than the untreated sample). Also, data revealed that $1.5 \%, 3 \%$ and $6 \%$ concentrations of aspirin inhibited the growth and reduced the expression of pyocyanin with slight various degrees (by $0.7955,0.4234,0.1948$-fold lesser than untreated sample, relatively). The results of this study could be useful in pharmacological intervention and clinical therapy as aspirin and $\mathrm{NaCl}$ could be combined with antimicrobial agents to treat Pseudomonas infections.
\end{abstract}

Key words: Pseudomonas aeruginosa; pyocyanin; sodium chloride; salicylic acid

\section{Introduction}

Pseudomonas aeruginosa ( $P$. aeruginosa) is a broad, Gram-negative bacterium that seizes the opportunity to infect the immunecompromised hosts including people infected by HIV, patients exposed to chemotherapy and patients suffering from severe burns (1).

The infection with $P$. aeruginosa gives rise to mortality in chickens and clinical symptoms including respiratory signs and septicemia (2). Proteases (elastase, protease, and alkaline protease), toxins (exoenzyme $\mathrm{S}$ and exotoxin A), hemolysins and phenazines are virulence factors in $P$. aeruginosa. They have been found to participate in $P$. aeruginosa pathogenicity in man and animals. Pyocyanin is a phenazine compound (5-N-methyl-1-hydroxy phenazine) considered as both a signal molecule and an important 
virulence factor. In cystic fibrosis lungs in vitro, pyocyanin interferes with the ciliary function of the respiratory system and can change the host immune response. Also, pyocyanin is considered as the last signal in the quorum-sensing (QS) system, and organizes many genes in $P$. aeruginosa (3).

Some compounds can inhibit the quorumsensing system such as salicylic acid (aspirin) (4). Aspirin can inhibit not only biofilm forming of $P$. aeruginosa, but also it can decrease the pyocyanin production (5). It has been reported that salicylic acid cause changes in the membrane of $P$. aeruginosa. Salicylic acid is regarded as an antimicrobial agent in the treatment of Pseudomonas keratitis (6).

Many environmental stimuli such as osmolarity, $\mathrm{pH}, \mathrm{NaCl}$ and the diversity of ions have a distinct influence on $P$. aeruginosa $(7,8)$. The swarming motility of the bacterium is affected by $\mathrm{NaCl}$. Bacterial growth is inhibited by $6 \% \mathrm{NaCl}$ solution. Bactericidal action occurs at $10 \% \mathrm{NaCl}$ solution (8).

16S rDNA-based PCR assays provide fast, plain and dependable identification of $P$. aeruginosa and its discrimination from other Pseudomonas species which are closely related in phylogenesis (9). Real-Time PCR (qPCR) was applied to study the fluorescence level in a particular selected gene. It is a highly sensitive technique that has remarkable potential for the high-volume analysis of gene expression in both research and routine medical diagnostics. This technique provides real-time quantitation of an initial template of DNA or RNA (10).

The present study was designed to illustrate the effect of $\mathrm{NaCl}$ and aspirin on an Egyptian $P$. aeruginosa strain isolated from septicemic broilers.

\section{Material and methods}

\section{The origin of the strain}

$P$. aeruginosa was isolated from broilers suffering from septicemia in Zagazig City, Egypt since 2017. P. aeruginosa was identified after examining for phenotypic and genotypic characteristics in the laboratory of microbiology department in Zagazig University. The isolate was maintained on Tryptone Soya Agar (Oxoid, CM0131, UK) (TSA) slopes at $5{ }^{\circ} \mathrm{C}$ and sub-cultured every month. $P$. aeruginosa was transferred on TSA slopes to Kafrelsheikh University at the laboratory of bacteriology.

\section{Determination of the effect of Sodium Chloride on P. aeruginosa}

$P$. aeruginosa subculture occurred in King A broth (Himedia M1544) supplemented with 30,60 , and $90 \mathrm{~g} / \mathrm{l}$ of $\mathrm{NaCl}$ (Bio Jet) to obtain $3 \%, 6 \%$, and $9 \%$ concentrations respectively. Cultures were incubated in a shaker incubator $\left(180 \mathrm{rpm}\right.$ at $\left.30^{\circ} \mathrm{C}\right)$ for $48 \mathrm{~h}$. The growth was determined visually and compared with the untreated sample of $P$. aeruginosa (3).

\section{Determination of the effect of aspirin}

$P$. aeruginosa subculture was occurred in nutrient broth overnight (PO) at $37^{\circ} \mathrm{C}$. Aspirin (100 mg, BAYER) was used. 2-fold serial dilutions in nutrient broth were prepared resulting in $100,50,25,12.5,6,3,1.5 \mathrm{mg} / \mathrm{ml}$ concentrations. Seven tubes each one contains $\mathrm{ml}$ from nutrient broth. In the first tube, one tablet from aspirin (aspirin protect $100 \mathrm{mg}$ ) was added. The concentration became $100 \mathrm{mg} / \mathrm{ml}$ in the first tube. $0.5 \mathrm{ml}$ from the first tube was taken to second tube giving concentration $50 \mathrm{mg} / \mathrm{ml}$ in the second tube. Repeat the same in other tubes giving the concentrations $25,12.5,6,3,1.5 \mathrm{mg} / \mathrm{ml}$ ). Then discard $0.5 \mathrm{ml}$ from the last tube. The last three tubes No. 5(D),6(E) and 7(F) contained 6,3,1.5\% Aspirin respectively. Diluted aspirin (D, E, F) was inoculated with 100 Micron PO containing 6 _ $105 \mathrm{CFU} / \mathrm{ml}$ and incubated at $37^{\circ} \mathrm{C}$ for $24 \mathrm{~h}$. Minimum inhibitory concentration (MIC) (the lowest concentration of antibacterial agent that inhibit the apparent growth of the bacteria) was measured. PO was treated with sub-inhibitory concentrations (sub-MIC) of aspirin (1/4 MIC). The number of viable emerged bacterial cells was estimated and collated to the number of untreated PO using the plating 
method (12). The growth of both PO treated with 1/4 MIC of aspirin and untreated PO was monitored. Inoculation of an overnight culture of PO into nutrient broth tubes treated with aspirin (1/4 MIC) and control ones without aspirin occurred. Incubation at $37{ }^{\circ} \mathrm{C}$ for $24 \mathrm{~h}$. Every hour, Optical Density $600 \mathrm{~nm}$ for treated and untreated samples was measured (4).

\section{Molecular identification}

The extraction of DNA was done by QIAamp DNA Mini kit instructions (Qiagen, Germany, GmbH, Catalog no. 51304) with some changes. Incubation of $200 \mu \mathrm{l}$ of the bacterial suspension occurred at $56^{\circ} \mathrm{C}$ for 10 min after addition of $10 \mu \mathrm{l}$ of proteinase $\mathrm{K}$ and $200 \mu \mathrm{l}$ of lysis buffer. Then, $200 \mu \mathrm{l}$ of ethanol $100 \%$ (Applichem) were appended to the lysate. The sample was washed and centrifuged according to the manufacturer's index. Then, elution of the nucleic acid occurred with $100 \mu$ of elution buffer presented in the kit. The reaction contained $25 \mu l$ of the following PCR master mix. Emerald Amp GT PCR master mix (2x premix) was $12.5 \mu$, PCR grade water was $4.5 \mu$ l. Forward primer (20 pmol) was $1 \mu \mathrm{l}$. Reverse primer (20 pmol) was $1 \mu \mathrm{l}$. Template DNA was $6 \mu \mathrm{l}$. The amplification of target gene phenazine (phzM) of Pseudomonas genus was performed using primer pair of phzM; 5'ATGGAGAGCGGGATCGACAG- ' 3 and 5'- ATGCGGGTTTCCATCGGCAG- '3 amplifying $875 \mathrm{bp}$ (13). The used primers were supplied from Metabion (Germany). Amplification cycles $(n=35)$ were performed under these conditions; primary denaturation for $5 \mathrm{~min}$ at $94^{\circ} \mathrm{C}$, secondary denaturation for $30 \mathrm{sec}$ at $94^{\circ} \mathrm{C}, 1 \mathrm{~min}$ of annealing at $54^{\circ} \mathrm{C}$ and $1 \mathrm{~min}$ of extension at $72^{\circ} \mathrm{C}$. Electrophoresis of amplified products in $1.5 \%$ agarose gel (ABgene) was done. The sizes of the amplified product were determined by a gene ruler 100 bp DNA Ladder (catalog No. SM0243) (Fermentas, Thermo Scientific, Germany). Photographing was done by Alpha imager (Innotech, Biomedia). A computerized analysis was performed.
RNA extraction for qPCR was done following RNeasy Mini Kit instructions (Qiagen, Catalog no. 74104) with some modifications. To protect RNA from degradation, a double volume $(1 \mathrm{ml})$ of the RNA protect Bacteria Reagent (Qiagen, Germany, GmbH Catalog no. 76506), was added to one volume $(0.5 \mathrm{ml})$ of the broth of $P$. aeruginosa culture, then the mix was incubated at room temperature for $5 \mathrm{~min}$. Then add $200 \mu 1$ of Tris EDTA buffer (TE buffer) (Thermo Fisher, Catalog no. 12090-015) containing $1 \mathrm{mg} / \mathrm{ml}$ Lysozyme (Biochemica, Applichem, Catalog no. A3711) and $700 \mu$ of lysis buffer. Then, 500 $\mu \mathrm{l}$ of $96 \%$ ethanol (Applichem) were added to the lysate. Washing and centrifugation of the sample were performed according to the manufacturer's index. Then, elution of RNA by $50 \mu \mathrm{l}$ RNase free water (Quantitect SYBR green PCR kit) (catalog. No .204141). The reaction contained $25 \mu \mathrm{l}$ of the $\mathrm{R}$ master mix according to Quantitect SYBR green PCR kit. QuantiTect SYBR Green PCR master mix (2x premix) was $12.5 \mu \mathrm{l}$. RevertAid Reverse Transcriptase (Thermo Fisher, Catalog number: EP0441) was $0.25 \mu \mathrm{l}$. Forward primer (20 pmol) was $0.5 \mu \mathrm{l}$. Reverse primer (20 pmol) was $0.5 \mu \mathrm{l}$. Template RNA was $3 \mu \mathrm{l}$. RNase free water was $8.5 \mu l$. The target genes: phenazine ( $p h z M)$ of Pseudomonas genus was performed using primer pair of phzM (mentioned previously), a primer pair of 16S rRNA gene;5' - GGGGGATCTTCGGACCTCA- ' 3 and 5'- TCCTTAGAGTGCCCACCCG- '3 (14). The following cycling condition protocol was used: $30 \mathrm{~min}$ for reversed transcription at $50{ }^{\circ} \mathrm{C}, 5 \mathrm{~min}$ for primary denaturation at $94{ }^{\circ} \mathrm{C}$, amplification cycles $(n=40)$ were performed under the following conditions; $15 \mathrm{~min}$ of secondary denaturation at $94^{\circ} \mathrm{C}$, annealing (Optics on) at $52{ }^{\circ} \mathrm{C}$ for $45 \mathrm{~min}$ for $16 \mathrm{~S}$ rRNA but at $54{ }^{\circ} \mathrm{C}$ for $45 \mathrm{~min}$ for $p h z M, 30 \mathrm{sec}$ for extension at $72{ }^{\circ} \mathrm{C}$, dissociation curve (one cycle) conditions; 1 min of secondary denaturation at 94 ${ }^{\circ} \mathrm{C}, 1 \mathrm{~min}$ of annealing at $52^{\circ} \mathrm{C}$ for $16 \mathrm{~S}$ rRNA but at $54{ }^{\circ} \mathrm{C}$ for $1 \mathrm{~min}$ for $p h z M, 1 \mathrm{~min}$ of final denaturation at $94{ }^{\circ} \mathrm{C}$. The curves of amplification and cycle threshold $(\mathrm{Ct})$ values 
were evaluated by the Stratagene MX3005P qPCR software. To assign the difference in the gene expression on the RNA of the samples, a comparison between the $\mathrm{Ct}$ of each sample and that of the control sample occurred according to the "2- $-\Delta \Delta$ Ct" equation (15).

\section{Results}

\section{The effect of $\mathrm{NaCl}$}

Growth appeared at 3\% concentration $\mathrm{NaCl}$ but no growth occurred at 6, $9 \%$. Growth turbidity at $3 \%$ concentration of $\mathrm{NaCl}$ was less than that of untreated sample.

\section{The effect of Aspirin}

Initially, the minimum inhibitory concentration of aspirin against $P$. aeruginosa $\mathrm{PO}$ was revealed as $24 \mathrm{mg} / \mathrm{ml}$. The sub-inhibitory concentrations of aspirin (1/4, 1/8 and 1/16 MIC) corresponding to 6,3 and $1.5 \mathrm{mg} / \mathrm{ml}$ concentrations of aspirin respectively were applied to evaluate the inhibitory influence on both quorum sensing system and the virulence factors of $P$. aeruginosa PO. The treated $P$. aeruginosa $\mathrm{PO}$ with sub-MIC of aspirin was as similar as the untreated PO in its viability. Example for that, the bacterial number was 154 _ $104 \mathrm{CFU} / \mathrm{ml}$ at 1/4 MIC in treated PO but the bacterial number of the untreated PO was 160 _ $105 \mathrm{CFU} / \mathrm{ml}$. Also, both treated and untreated PO attained a stationary phase after incubation for $9 \mathrm{~h}$ at $37^{\circ} \mathrm{C}$, signifying no impact on the growth. But the bluish metallic sheen OF $P$. aeruginosa (11) was changed to some extent.
Turbidity degree was inversely proportional with the concentration of Aspirin. Treated Pseudomonas with 1/4 MIC showed the least turbidity. The turbidity of treated Pseudomonas with

1/16 MIC was lesser than the untreated sample.

\section{Polymerase Chain Reaction}

PCR reaction was done to diagnose $P$. aeruginosa using $16 \mathrm{~S}$ rDNA. The results showed that one band $875 \mathrm{bp}$ (product size) as a result of agarose gel compare with DNA marker (100 bp) (figure 1).

\section{Quantitative real-time PCR}

The fluorescence light emitted within qPCR is directly proportional to the formed DNA and can be assumed as an amplification plot. As a result of $\mathrm{Ct}$ values (table 1), the data revealed that $3 \%$ concentration of $\mathrm{NaCl}$ reduced the expression of $P h z M$ (by 0.5 -fold less than the untreated sample). The reduction percentage of $P h z M$ was $50 \%$. But for Aspirin, $1.5 \%, 3 \%$ and $6 \%$ concentrations caused decrease in the expression of pyocyanin with various degrees (by $0.7955,0.4234$, 0.1948 -fold less than untreated sample relatively), i.e., the reduction in expression of PhzM with $80.52 \%, 57.66 \%$ and $20.45 \%$ in sub MIC $(1 / 4(6 \mathrm{mg} / \mathrm{ml}), 1 / 8(3 \mathrm{mg} / \mathrm{ml})$ and $1 / 16(1.5 \mathrm{mg} / \mathrm{ml}))$ of Aspirin respectively (chart1). The experiment had been repeated three times. The amplification curve of 16SrDNA (figure 2) but that of $P h z M$ (figure 3) were showed.

Table 1: The Ct values of 16SrDNA and PhzM for each sample with the fold change of them were analyzed. The Control sample was the untreated isolated $P$. aeruginosa

\begin{tabular}{ccccc}
\hline Sample & Sample ID & 16S rDNA & \multicolumn{2}{c}{$p h z M$} \\
\cline { 3 - 5 } No. & & & & \\
& & CT & CT & Fold change \\
\hline B & Control & 19.78 & 22.86 & - \\
C & NACL 3\% & 20.84 & 24.92 & 0.5000 \\
D & Aspirin 6\% & 20.39 & 25.83 & 0.1948 \\
E & Aspirin 3\% & 19.21 & 23.53 & 0.4234 \\
F & Aspirin 1.5\% & 20.54 & 23.95 & 0.7955 \\
\hline
\end{tabular}




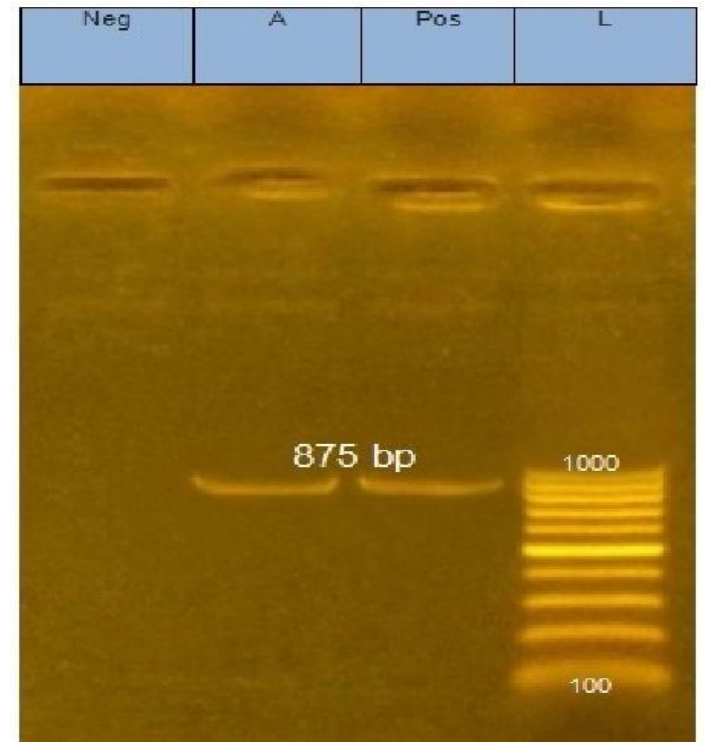

Figure 1: agarose gel electrophoresis of pyocyanin gene amplification of Pseudomonas aeruginosa strain. L: 100bp ladder. Lane (A): positive sample. Pos: positive control and neg: negative control. Positive and /or negative controls were represented by field sample that was previously confirmed to be positive or negative by PCR for the related gene in the Reference laboratory of Animal health research institute, Zagazig University. Amplicon size: 875 bp

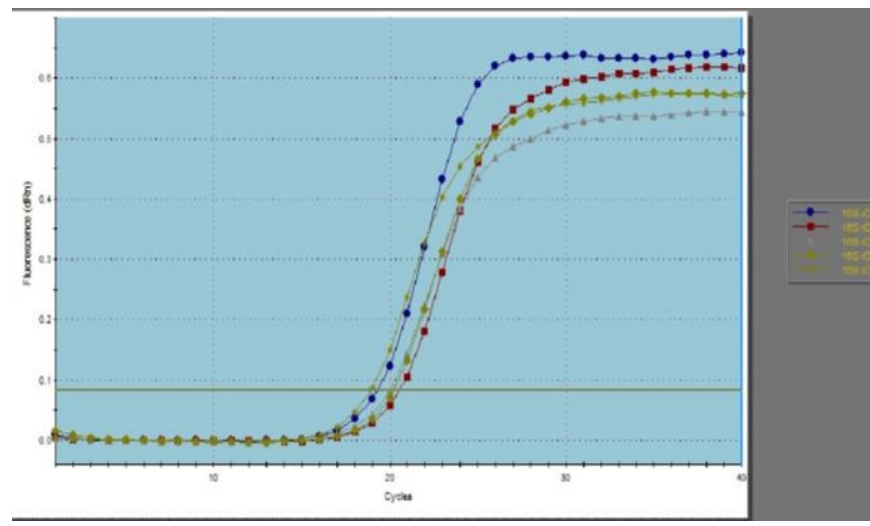

Figure 2: Amplification curve of 16SrDNA. X-axis: amplification cycles. Y-axis: distinctive fluorescence. The axis that was parallel to $\mathrm{X}$ axis was a threshold axis. Each point of each sample of the curve which crossed the threshold axis was the $\mathrm{Ct}$ value

\section{Discussion}

In the present study, the influence of $\mathrm{NaCl}$ and Salicylic acid on the $P$. aeruginosa growth and expression of pyocyanin virulence factor of it was investigated. Results demonstrated

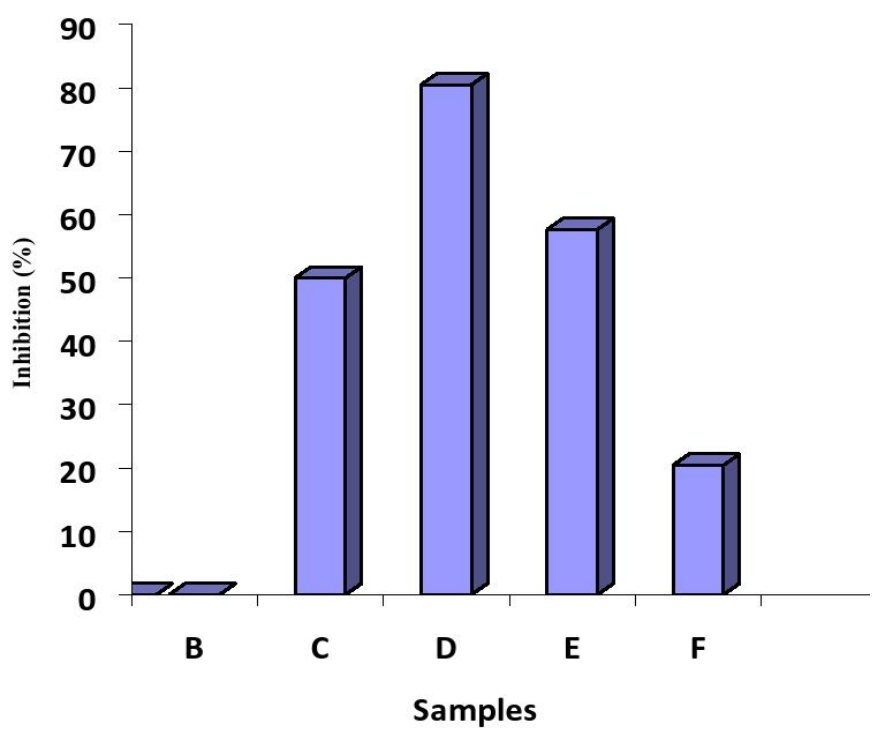

Chart 1: The inhibition percentage of $P h z M$ expression in each sample. B: control (untreated sample). C: a sample containing $\mathrm{NaCl} 3 \%$. D: a sample containing Aspirin 6\%. E: a sample containing Aspirin 3\%. F: a sample containing Aspirin 1.5\%

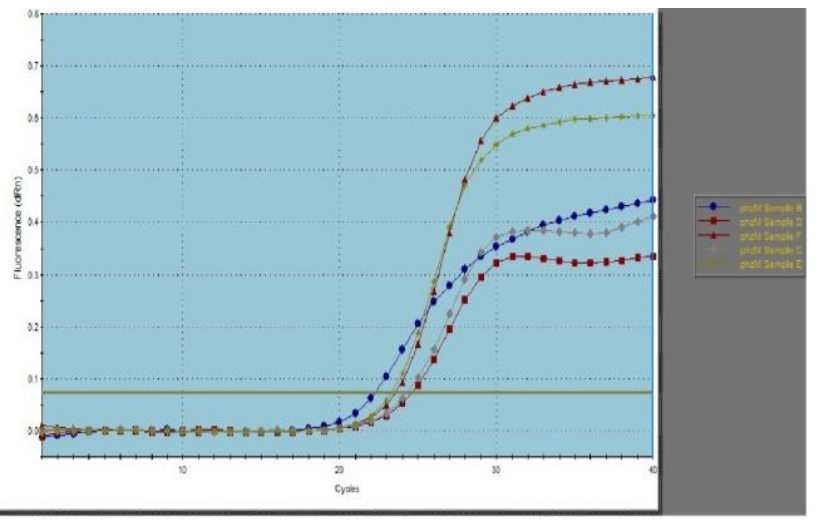

Figure 3: Amplification curve of $P h z M$. X-axis: amplification cycles. Y-axis: distinctive fluorescence. The axis that was parallel to $\mathrm{X}$-axis is threshold axis. Each point of each sample of the curve which crossed the threshold axis was $\mathrm{Ct}$ value

that $\mathrm{NaCl}$ and Aspirin had a significant impact on the $P$. aeruginosa growth and pyocyanin production. This study revealed that $6 \%$ and $9 \%$ concentration of $\mathrm{NaCl}$ had a bactericidal effect on the bacterium but $3 \%$ concentration of $\mathrm{NaCl}$ has an inhibitory effect on the growth 
and also on the expression of Pyocyanin (by 0.5 -fold lesser than the untreated sample). The reduction percentage of $P h z M$ was $50 \%$. But for Aspirin, $1.5 \%, 3 \%$ and $6 \%$ concentrations caused inhibition of growth and decrease in the expression of pyocyanin with slight various degrees (by 0.7955, 0.4234, 0.1948 -fold lesser than untreated sample relatively), i.e., the reduction in expression of $P h z M$ with 80.52 $\%, 57.66 \%$ and $20.45 \%$ in sub MIC (1/4 $(6 \mathrm{mg} / \mathrm{ml}), 1 / 8(3 \mathrm{mg} / \mathrm{ml})$ and $1 / 16(1.5 \mathrm{mg} / \mathrm{ml})$ of Aspirin respectively.

Previous studies revealed that Pseudomonas influenced by a different concentration of salinity. Pyocyanin production increased proportionally with salinity concentration. The high amount of pyocyanin $(29.57 \mu \mathrm{g} / \mathrm{ml})$ was obtained with $20 \mathrm{~g} / \mathrm{L}$ of $\mathrm{NaCl}$ ( $2 \%$ concentration). The result also indicated that salinity above $20 \mathrm{~g} / \mathrm{L}$ have totally affected pyocyanin production but did not affect the bacterium growth which was completely inhibited at $60 \mathrm{~g} / \mathrm{L}$ of $\mathrm{NaCl}$ (6\% concentration). The production of pyocyanin was salinity-dependent when $P$. aeruginosa had grown in King A medium supplemented with 2.5 to $20 \mathrm{~g} / \mathrm{l}$ of $\mathrm{NaCl}$. The highest amount of pyocyanin was obtained at $20 \mathrm{~g} / \mathrm{l}(2 \% \mathrm{NaCl})$ and the growth of P. aeruginosa was completely inhibited at $50 \mathrm{~g} / \mathrm{l}$ of $\mathrm{NaCl}(5 \% \mathrm{NaCl})$ (3); However, another study showed that maximum of productivity was found in a medium salinity ranging from 5$10 \mathrm{~g} / \mathrm{l}$. but at concentration $5 \mathrm{~g} / \mathrm{l}$ or less, there was not significantly inhibition of the growth and the pyocyanin production. $(16,17)$.

Other studies revealed that the normal growth of $P$. aeruginosa appeared on a medium which contained 0.25 up to $1.25 \%$ concentration of $\mathrm{NaCl}$ in comparison to control medium. Above $1.75 \% \mathrm{NaCl}$ concentration in the medium, it can survive up to $2.75 \% \mathrm{NaCl}$ but the survival number of Pseudomonas gradually reduced. The inhibition impact was observable at a solution containing $4 \%$ concentration of $\mathrm{NaCl}$. A solution containing $6 \%$ concentration of $\mathrm{NaCl}$ could inhibit the growth of Pseudomonas after incubation for $24 \mathrm{~h}$. The bactericidal effect on Pseudomonas occurred by $8 \%$ and $10 \%$ of $\mathrm{NaCl}(18,8)$.
For patients suffering from cystic fibrosis in the lung, aerosols containing hypertonic saline $(7 \% \mathrm{NaCl})$ are useful in the treatment due to abolish both motility and growth of $P$. aeruginosa (19).

Salicylic acid can inhibit production of pyocyanin $(4,6)$. Distinct reduction in the virulence factors of $P$. aeruginosa treated with 6 $\mathrm{mg} / \mathrm{ml}$ (1/4 MIC) and $3 \mathrm{mg} / \mathrm{ml}$ (1/8 MIC) concentrations of aspirin. Pyocyanin reduction was $78 \%$ due to treating with aspirin (1/4 MIC) (4). Growth in the sub-inhibitory concentrations of salicylic acid resulted in a significant reduction in bacterial cell number, cell density and in quorum-sensing signaling molecules (20). Salicylic acid plays a role in downregulating some of the virulence factors (especially pyocyanin) in P. aeruginosa and attenuating the virulence of the bacterium on Caenorhabditis elegans and Arabidopsis thaliana. A $50 \%$ reduction of Pyocyanin production was resolved after treatment with $0.1 \mathrm{mM}$ salicylic acid but an $80 \%$ reduction of pyocyanin production with no visible influence on the bacterial growth was determined after treatment with $1.0 \mathrm{mM}$ SA $(20,21)$.

Another study revealed that $P$. aeruginosa 1604 was still able to produce a considerable amount $(0.44 \mu \mathrm{gml}-1)$ of pyocyanin after a 72 hours lag period in the presence of $0.1 \%$ aspirin. At $0.3 \%$ concentration, the inhibitory effect was evident for 120 hours. For long-term inhibitions, a higher amount of applied salicylic compounds (0.3 and $0.4 \%)$ are necessary (5). Salicylic acid can reduce bacterial numbers and its virulence during keratitis so it is effective as an antimicrobial substance to treat Pseudomonas keratitis (6).

\section{Conclusion}

In this study, $P$. aeruginosa isolate was from broilers suffering from septicemia in Zagazig city, Egypt. By using PCR and qPCR, the data revealed that Aspirin and Sodium chloride inhibit the $P$. aeruginosa growth and decrease pyocyanin production. This new therapeutic approach can be used in combination with antimicrobial agents to treat $P$. aeruginosa cases. 


\section{Conflict of interest}

None of the authors disclose any conflict of interest.

\section{References}

1. El-Domany $\mathrm{R}$, Emara $\mathrm{M}$, El-Magd $\mathrm{M}$, Moustafa W, Abdeltwab N. Emergence of Imipenem-Resistant Pseudomonas aeruginosa Clinical Isolates from Egypt Coharboring VIM and IMP Carbapenemases, Microbial Drug Resistance 2017; 23(6): 682-6.

2. Satish S, Priti M. Pseudomonas aeruginosa Infection in Broiler Chicks in Jabalpur. International J Ext Res 2015; 6:37-9.

3. Hicham D, Rachid D, Saïd N. Antimicrobial, antioxidant and hemolytic effects of Pyocyanin produced by Pseudomonas aeruginosa isolated from saline soil of Mina river, Algeria. International J of Biosciences 2016; 9(5): 134-43.

4. Somaia A, Khaled H, Shahenda M, Mona I. Aspirin is an efficient inhibitor of quorum sensing, virulence and toxins in Pseudomonas aeruginosa. Microbial Pathogenesis J. 2014; 74:25-6.

5. Ágnes D, Hajnalka F, Ákos K, Petra S, Péter k. Inhibition of exopolysaccharide biopolymer and pyocyanin virulence factors produced by Pseudomonas aeruginosa 1604 by salicylic compounds, Periodica Polytechnica Chemical Engineering J. 2014;58:75-80.

6. Mahesh B, Padmaja S, Hua Z, Emma H, Mark W. Effect of Salicylic Acid on the Membrane Proteome and Virulence of Pseudomonas aeruginosa. Cornea J. 2016; 57:1213-20.

7. Rahul M, Sudhir A, Saroj S, Sanjay C and Kusum H. Urinary tract infections caused by Pseudomonas aeruginosa. Journal of Infection and Public Health 2009; 2: 105.

8. Anne-Laure M, Estelle JB, Raphae C, Brigitte $\mathrm{L}, \mathrm{He}^{\prime}$ le'ne $\mathrm{M}$. Advances toward the Elucidation of Hypertonic Saline Effects on Pseudomonas aeruginosa from Cystic Fibrosis Patients. PLOS ONE J. 2014; 9(2): e90164.

9. Mohammed EA, Ismail HA, Abeer AM. Identification Pseudomonas aeruginosa by $16 \mathrm{~s}$ rRNA gene for Differentiation from Other Pseudomonas Species that isolated from Patients and Environment. Baghdad Science J.2014; 11(2):1028-33.

10. Crystal AC. Study of Secondary Metabolite Gene Expression in Marine Microbial Co-Cultures Using Quantitative Real-Time PCR. Nova Southeastern University Works. HCNSO Student Theses and Dissertations. Oceanographic Center 2010; 222: 4-187.

11. Quinn PJ, Markey BK, Carter ME, Donnelly WJ, Leonard FC. Veterinary Microbiology and Microbial Disease. $2^{\text {nd }} E d$, 2011:287.

12. Sanders ER, Aseptic laboratory techniques: plating methods. Journal of Visualized Experiment 2012 ; ( 63): e3064.

13. Finnan S, Morrissey JP, Gara, FO, Boyd EF. Genome Diversity of Pseudomonas aeruginosa Isolates from Cystic Fibrosis Patients and the Hospital Environment. Journal of Clinical Microbiology 2004; 42:5783-92.

14. Spilker T, Coenye T, Vandamme P, LiPuma JJ. PCR-Based Assay for Differentiation of Pseudomonas aeruginosa from Other Pseudomonas Species Recovered from Cystic Fibrosis Patients. Journal of Clinical Microbiology 2004; 42(5):2074-9.

15. Yuan JS. Reed A, Chen F, Stewart CN. Statistical analysis of real-time PCR data. BMC Bioinformatics J. 2006; 7:85.

16. Akpor OB, Morah BL, Adejobi O, Oloninefa SD, Babalola OO. Tolerance of Pseudomonas aeruginosa to selected concentrations of metals and Sodium Chloride. CIBTech Journal of Microbiology 2015; 4(3):27-33.

17. Prabhakaran P, Puthumana J, et al. Antagonistic effect of Pseudomonas aeruginosa isolates from various ecological niches on Vibrio species pathogenic to crustaceans. Journal of Coastal Life Medicine 2014; 2(1):76-84.

18. Vishal KD, Punkaj K. Effect of Salinity on Growth and PGPR Activity of Pseudomonads. Journal of Academia and Industrial Research 2013; 2(6): 353-6.

19. Viktória H, Eric S, et al. Inhibitory Effects Of Hypertonic Saline On P. Aeruginosa Motility. NIH Public Access. J Cyst Fibros 2008; 7(4): 267269.

20. Mahesh BK, Hua Z, Padmaja RS, Mark DP. Salicylic Acid Reduces the Production of Several Potential Virulence Factors of Pseudomonas aeruginosa Associated with Microbial Keratitis. Investigative Ophthalmology \& Visual Sci J. 2006; 47(10):4453-60.

21. Prithiviraj B, Bais HP, et al. Down Regulation of Virulence Factors of Pseudomonas aeruginosa by Salicylic Acid Attenuates Its Virulence on Arabidopsis thaliana and Caenorhabditis elegans. Infection and Immunity. American Society for Microbiology J.2005; 73(9): 5319-28. 